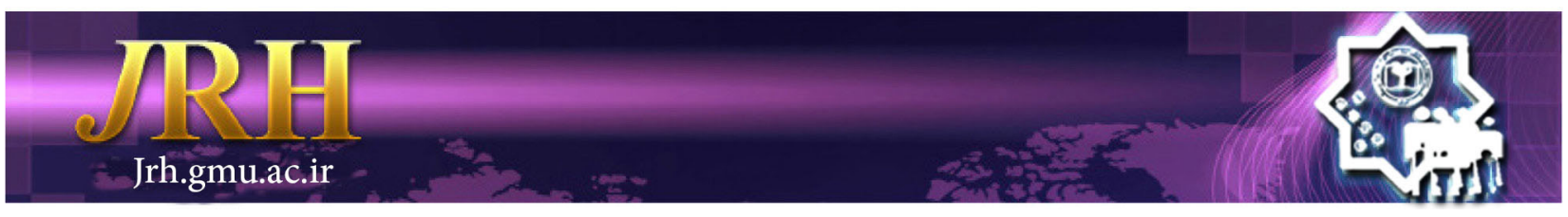

\title{
Psychometric properties of brief histrionic personality symptoms scale among Iranian students
}

\author{
Journal of Research \& Health \\ Social Development \& Health Promotion \\ Research Center \\ Vol. 9, No. 5, Sep \& Oct 2019 \\ Pages: $411-417$ \\ DOI: $10.29252 / j r h .9 .5 .411$ \\ Original Article
}

1. Correspondence to: Behavioral Sciences Research Center, Lifestyle Institute, Baqiyatallah University of Medical Sciences, Tehran, Iran

Email: Amirysohrab@yahoo.com

2. Department of Counseling, Faculty of Psychology and Educational Sciences, Isfahan University, Isfahan, Iran

Received: 30 Jan 2017 Accepted: 15 Apr 2018

How to cite this article: Amiri S, Jamali Y. Psychometric properties of histrionic personality symptoms scale among Iranian students. J Research Health2019; 9(5): 411417.
Sohrab Amiri ${ }^{1}$, Yusef Jamali ${ }^{2}$

\begin{abstract}
Histrionic personality is a personality disorder in the international classification of disease and diagnostic and statistical manual of mental disorders. This study was aimed to evaluate the psychometric properties of brief histrionic personality symptoms scale (BHPS). 322 university students were selected by using multistage cluster sampling. Initially the questionnaire was translated (backward and forward). Reliability of the scale was assessed by Cronbach's alpha, test-retest and splitting coefficient, which were 77.0, 89.0, 56.0, 49.0, 67.0, 71.0. The criterion validity was done with histrionic personality subscale from millon clinical multiaxial inventory and five-factor personality inventory. As well as its factor structure was assessed by using exploratory and confirmatory factor analysis, fit indexs of $\mathrm{X}^{2} / \mathrm{df}$ equal to $3.2, \mathrm{SRMR}=0.07$, $\mathrm{CFI}=0.90$ and RMSEA $=0.10$. The results of the factor analysis indicated that BHPS has 2 factors, test the reliability of the scale by using Cronbach's alpha, retest and splitting coefficient reflects the reliability of the scale, the criterion validity of the questionnaire with other questionnaires showed desirable discriminant and convergence validity. In Overall, these findings indicated BHPS has good psychometric properties among Iranian students.
\end{abstract}

Keywords: Histrionic, Personality, Reliability, Scale, Validity

\section{Introduction}

The histrionic personality has been showed in both the international classification of diseases and health problems [1] and the Diagnostic and Statistical Manual of Mental Disorders (DSM-5) [2]. Histrionic Personality Disorder (HPD) is a clinical syndrome in which people have an interactive style interpersonal style which is characterized by seduction, emotional superficiality, and displaying by seductiveness, emotional superficiality, and dramatics [2]. According description in the DSM-5; [2], people with HPD have being motivated by a search for being the center of attention; these are seductive, flirting and excite other people's sex, high self-expression in expressing emotions also has an emotional superficiality and ignores the others feelings that these people often describe themselves as attractive 
people and may perform sexually suggestive behaviors. People with histrionic personalities often have high social and occupational functioning, despite being easily influenced by others and tend to use their skills to control and manage others but showing good social skills [3-5]. Because of the nature of being dramatic and extraversion, people with HPD may have some fans, although they often have problems in maintaining a deep and mutually satisfactory relationship. The prevalence of this disorder in the general population is estimated at 2-3\% [6]. This disorder is often diagnosed in women [4], although some studies have reported the equal prevalence in both genders [7].

Kraus and Reynolds [6] stated that histrionic personality disorder was associated with an increased risk for a variety of disorders, including depression and anxiety and argue that HPD can be an important clinical syndrome for study. It has been shown that histrionic personality is associated with a number of negative consequences including reduced marital satisfaction and success [8] and higher rates of depression disorder [9]. Compared to other Class B personality disorders, few researches have been focused on HPD. Although there may be several reasons that have been less addressed to HPD that one reason may be due to the lack of a HPD symptom scale is available and at the same time concise, short, and valid.

Clinical Multidimensional Millon Clinical Questionnaire (MCMI) [10] is the only clinical test involving a histrionic scale. On the contrary, the Minnesota Personality Invetory [11] does not include any scale from the HPD, although histrionic personality traits may be inferred from scales. Colligan, Morey and Offord [12] developed a prestigious histrionic scale for MMPI. However, due to the lack of scoring pattern this scale is inappropriate for clinicians. Both the MCMI-III and the MMPI-2 are long because of their large personality scales and its scoreing on the histrionic scale of MMPI-2 is inappropriate. In this way, it seems that a clinical measure scale for HPD traits that is concise, valid, accessible, and easy to scoreing for clinical and research populations is necessary.
Accordingly, Ferguson and Nogee [13] formulated a screening scale to measure brief histrionic personality symptoms. This scale consists of 11 questions and two subscales of seductiveness and attention seeking which is standardized on two samples of 661 and 340 adults that results have shown this scale has favorable psychometric properties and hence it can be used as a valid tool to measure histrionic personality traits. As above, despite the fact that histrionic personality traits have clinical significance, however the study of these traits due to the lack of appropriate tools doesn't have enough research and clinical attention so the purpose of this study was to evaluate the psychometric properties Brief Histrionic Personality Symptom Scale (BHPS) among Iranian university students.

\section{Method}

The population of the study was all students of Bu-Ali Sina university in Hamedan, Iran, in 2016-2017 academic years. The participants of the study were 322 students who were selected by multistage cluster sampling among faculties (full-time, tuition-based program and part-time). Data were gathered using survey method (questionnaire).

Brief Histrionic Personality Symptom Scale (BHPS): Initially, in order to shape the histrionic personality scale, a set of 36 items was selected that had DSM-5 criteria for the identification of histrionic personality disorder. Questions should be responded based on the 4-level Likert spectrums are never to ever. After exploratory factor analysis using maximum likelihood method with promax rotation 11 times with higher 0.60 factor load was extracted. Based on this, factor analysis yielded two-factor solution. 11 items had alpha coefficients of 0.76 . Seductiveness subscale has been shown alpha coefficient of 0.67 and subscale of attention seeking 0.74 [13]. In order to prepare the Persian version of the BHPS [13], the researcher and two English language experts translated the questionnaire to Persian then the back translated text was revised. In the next step, the translated text, translated into 
English by the researcher and English language experts and the two versions were matched to each other. Then, the questionnaire was given two psychology experts to test its Facial Validity. After the match between the translated version and the original and solving the defects, questionnaire was implemented on 40 students similar to the final research community and then getting the feedback about the content of the items and fixing the weaknesses the final version of the questionnaire was prepared for use.

MultidimensionalMillon ClinicalQuestionnaire-3 (MCMI-III): A self-assessment scale with 175 items which evaluates 14 clinical patterns of personality and 10 clinical syndromes and is used for adults aged 18 or over for therapeutic or psychological evaluation. Its validity has been confirmed through factor analysis and its reliability has been confirmed through internal consistency and proper test-retest. The retest reliability coefficient was reported at a median of 0.91 . The range of retest coefficients was between 5 and 14 days [14]. Khajeh Mughi [15] conducted a study in order to standardize this test in Tehran. In this study, the reliability coefficient of MCMI scales was obtained from a range of 7 to 10 days from a range of 0.78 (dramatic scale) to 0.87 (delusional disorder scale).

Neo Personality Questionnaire (NEO): This questionnaire is a sixty-item that can measure five main factors and six attributes of each factor. In this form, participants receive a score of 0-4 in each sentence and every twelve questions are one of the factors of scale [16]. McCrae and Costa in 1992 reported Cronbach's Alpha coefficients of 0.66 for agreeableness to 0.86 for Neuroticism [16]. This test has been implemented and standardized in Iran by Hagnosh, whose desirable Cronbach's alpha coefficients have been reported in 512 participants [17].

In order to collect data, the researcher first described the response process and then distributed tools to answer among the participants. During the research process, the researcher was present among the participants in order to ensure the accuracy of the response, as well as to resolve the ambiguity. Data were analyzed by SPSS-22 and LISREL 8.8 [18]. Psychometric indicators of the BHPS were calculated through descriptive indexes, cronbach's alpha coefficient, twohalf coefficient and test-retest correlation coefficien, confirmatory factor analysis.

\section{Results}

Of the participants, the number of undergraduate students was $194(60.3 \%)$, the master degree was $106(32.9 \%)$ and $22(6.8 \%)$ were $\mathrm{PhD}$. The descriptive and demographic characteristics of the participants showed that 65 boys (20.2\%), 257 girls (79.8\%), as well as means and standard deviations was obtained for boys age 72.21 (30.2) and for girls 29.21 (18.2) respectively.

Validity of Persian version of the BHPS [13] was investigated with two methods of critical validity Simultaneous implementation with histrionic personality subscale from Millon clinical multiaxial inventory [14] and The big five-factor personality inventory [16], and the correlation between subscales (Table 1).

Table 1 Correlation coefficients between subscales of histrionic personality signs with other scales

\begin{tabular}{lcccccccc}
\hline Subscales & 1 & 2 & $\begin{array}{c}\text { Hysteric } \\
\text { (million) }\end{array}$ & Extroversion & Conscientiousness & Agreeableness & Neuroticism & Openness \\
\hline $\begin{array}{l}\text { Seductiveness } \\
\begin{array}{l}\text { Attention } \\
\text { seeking }\end{array}\end{array}$ & $0.54^{* *}$ & - & $0.38^{* *}$ & $0.29^{* *}$ & -0.08 & 0.07 & $0.11^{* *}$ & $0.13^{* *}$ \\
\hline
\end{tabular}

$* * \mathrm{p}<0.01 * \mathrm{p}<0.05$

The pattern of correlation coefficients between subscales in Table 1 shows that there is a proper internal relation between subscales. Also, the correlation coefficient model of the subscales with the histrionic personality subscale from
Millon vlinical multiaxial inventory [14] and The big five-factor personality inventory [16] indicates the simultaneous validity of the BHPS [13].

In order to investigate the fitting of the two- 
factor structure of the Persian version of the BHPS [13], a confirmatory factor analysis using maximum likelihood method and the LISREL software was used [18].
The path diagram of the confirmatory factor analysis along with the path coefficients in Figure 1 and also the $\mathrm{T}$ index in Table 2 has been presented.

Table 2 T Index for evaluation of significant level

\begin{tabular}{lccccc}
\hline Subscales & ITEM & T index & Subscales & ITEM & T index \\
\hline & 1 & 11.75 & & 2 & 11.35 \\
& 4 & 2.61 & & 3 & 6.44 \\
Seductiveness & 5 & 4.73 & Attention & 6 & 7.53 \\
& 9 & 6.28 & seeking & 7 & 11.55 \\
& 10 & 7.84 & & 8 & 10.09 \\
& 11 & 9.73 & & &
\end{tabular}

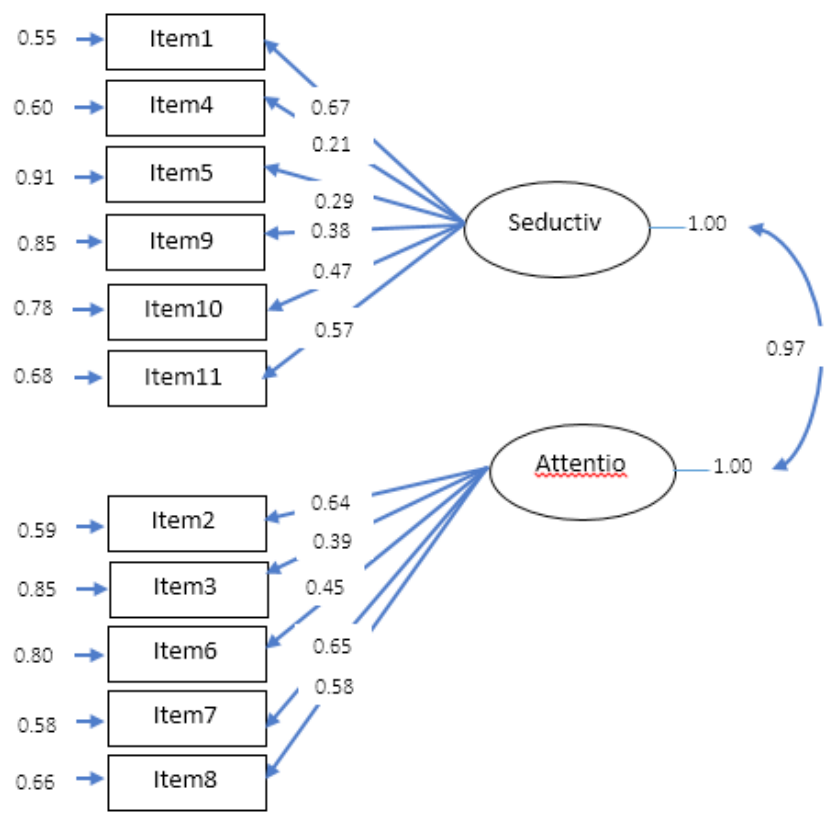

Figure 1 Confirmatory factor analysis graph and path coefficients of histrionic personality symptom scale

Table 3 Fitness indices of histrionic personality symptom scale

\begin{tabular}{ccccccccccccc}
\hline Index & $\mathrm{X}^{2}$ & $\mathrm{df}$ & Value & RMSEA & SRMR & NFI & NNFI & RFI & IFI & GFI & AGFI & CFI \\
\hline Value & 138.50 & 43 & $<0.05$ & 0.10 & 0.07 & 0.80 & 0.80 & 0.76 & 0.84 & 0.90 & 0.84 & 0.84 \\
\hline
\end{tabular}

The confirmatory factor analysis by using LISREL software offered 3 levels of fit indices [19,20]: 1) absolute fit indices such as Chi-square index and Standardized Root Mean Square Residual (SRMR), 2) parsimony goodness-of-fit index such as Root Mean Square Error of Approximation (RMSEA) and 3) Comparative Fit Index (CFI). There is controversy over the precise cutting scores of fit indices [19-23]. More the scores of Normed Fit Index (NFI), Relative Fit Index
(RFI), and Goodness of Fit Index (GFI) are closer to 1; they indicate the pattern's more desired fit. In the present study, the most valid fit scores have been used in order to assess the model's fit. SRMR $<0.08$ shows a desired fit and SRMR $<0.10$ indicates an acceptable fit and the model is failed when $S R M R>0.10$ [22]. The index with value of RMSEA $\leq 0.8$ shows the model is good, and when the RMSEA is between 0.10 and 0.08 , the model is acceptable. Eventually, 
$\mathrm{CFI} \geq 0.95$ states the good fit of the model [22]. Since the $X^{2}$ statistic is sensitive to the sample size, to assess the overall fit of the model, the amount of $\mathrm{X}^{2}$ is calculated along with the degree of freedom $\left(\mathrm{X}^{2} / \mathrm{df}\right) . \mathrm{X}^{2} / \mathrm{df}<2$ represent the model's good fit and when X2/ $\mathrm{df}$ is around 3, the model is acceptable. The amount of $\mathrm{X}^{2} / \mathrm{df}$ was 3.2, which is around 3, so the model's fit is acceptable. In addition to this, SRMR $=0.07$ showed the 6 factor model's fit is acceptable and the fit indices of CFI $=0.90$ and $\mathrm{RMSEA}=0.10$ represent the model's acceptable fit.

To assess the reliability of the BHPS [13], the Cronbach's Alpha coefficient, Two-half coefficient and test-retest were calculated. The Cronbach's alpha coefficient of 11 questions was 0.75 , indicating that the scale had good internal consistency. Also, two-half coefficients of the total scale 0.77 and its subscales 0.67 and 0.71 showed good consistency of the scale and its sub-scales.

In order to calculate the retest coefficient, 47 participants responding to the questionnaire two weeks later and correlation coefficient between two times the implementation of the questionnaire was calculated. The results of the Cronbach's alpha coefficient, the two-half and test-retest coefficient would be presented in Table 4.

The results of Table 4 show that the Cronbach's alpha coefficients are satisfactory and also the data of all the coefficients of the retest and the two half-sets are significant. Therefore, it can be concluded that the Persian version of the BHPS [13] has a favorable internal consistency.

Table 4 Mean, standard deviation, alpha coefficients, and histrionic personality symptoms subscales

\begin{tabular}{lccccc}
\hline Subscale & ITEM & M/SD & $\begin{array}{c}\text { Alpha } \\
\text { coefficient }\end{array}$ & $\begin{array}{c}\text { Retest coefficients } \\
(\mathrm{N}=47)\end{array}$ & $\begin{array}{c}\text { Two-half } \\
\text { coefficient }\end{array}$ \\
\hline Seductiveness & $1,4,5,9,10,11$ & $12.11(3.03)$ & 0.77 & $0.56^{* *}$ & 0.67 \\
Attention seeking & $2,3,6,7,8$ & $12.48(2.98)$ & 0.89 & $0.49 * *$ & 0.71 \\
\hline$* * p<0.01$ & & & &
\end{tabular}

\section{Discussion}

The present study evaluates the Psychometric properties of the BHPS. The present findings provide clear support for the reliability and validity of the BHPS as new questionnaire to eliminate the limitations of existing questionnaires and valid measurement of histrionic personality traits. As expected from previous studies [13], factor analysis of BHPS showed that the two-factor solution has a desirable fit. This finding is consistent with studies which examined the factor structure of the BHPS [13]. In addition, the results showed that two sub-scales include: 1) Seductiveness 2) Attention seeking has a favorable internal reliability. Investigating the factor structure and factor load patterns of the BHPS, using the confirmatory factor analysis, obtained similar results to Ferguson and Negy [13] two-factor solution. Therefore, the findings of this study are consistent with the results of Ferguson and Negy's research [13] that shows the BHPS has a desirable structure.

The study of the reliability of the BHPS, by calculating the alpha coefficients, the coefficients of test-retest and Two-half coefficient indicated a desirable reliability of this scale. Alpha coefficients of subscales: 1) Seductiveness 2) Attention seeking were 0.77 and 0.89 , respectively. And the re-test and the two-half coefficient indicate the desirability of the reliability of the BHPS; these findings are in line with the study of Ferguson and Negy [13] research which formed the original version of the BHPS.

The validity of the histrionic personality trait scale with histrionic personality subscale of Millon Clinical Multiaxial Inventory [14] shows positive correlation coefficients among all the similar subscales in the histrionic personality scale scale and the histrionic personality subscale $(p<0.01)$ this result demonstrates the convergence validity of the BHPS.

Psychometric properties of brief histrionic personality symptoms scale in the present study are consistent with studies in the 
original version [13]. According above, the lack of a specific and useful instrument for measuring histrionic personality dimensions is one of the weaknesses in the field of personality research. Consequently, regardless of language and culture, and considering the pattern of factor loads consistent with previous studies [13], the histrionic personality scale seems to be a useful tool for better understanding the histrionic fundamental constituents of the personality. Generally, reliability, validity and confirmatory factor analysis revealed the desirable psychometric characteristics of brief histrionic personality symptoms scale and the findings of the present study are consistent with the results of the original version [13] and that the Persian version of the histrionic personality symptom showed that it was a reliable tool for assessing the dimensions of histrionic traits. Also, the calculated indices for the fitting of the histrionic personality marker scale model showed that SRMR (RMSEA), (X2/df) as the most prestigious fitness indicators [19-23] support the fitting of the model. This finding was in line with the results of the original version of the BHPS [13]. So according to what was said, the present study was conducted among the student population. It is also recommended that in future research; the validity of the BHPS should be studied using other clinical approaches. Although the present study mainly focused on brief histrionic personality symptoms scale from the self-report perspective, however, adding information from clinical practices could be attractive and provide more information. On the other hand, information was gathered in a cross-sectional manner, thus limiting the conclusion about the observed effects. So future studies should have focus on longitudinal research. In total the result of this study showed that the validity and reliability of the histrionic personality trait scale in the sample of normal Iranian population. In addition, the factor structure of the questionnaire was consistent with the theoretical view of its makers and the two factors extracted based on the confirmatory factor analysis were in line with the original version of the BHPS.
Despite the limitations expressed, the present findings show that the BHPS can measure the components of histrionic personality and distinguish between their dimensions.

\section{Conclusion}

Brief histrionic personality symptoms scale has the good psychometric properties and applicability in Iranian students.

\section{Acknowledgments}

The authors of the article need to acknowledge the cooperation and assistance of all the loved ones who helped us in this research.

\section{Authors' contributions}

Study design: AS

Data collection and analysis: AS, YJ

Manuscript preparation: AS, YJ

All authors have read and approved the final version.

\section{Conflict of Interest}

"The authors declare that they have no competing interests."

\section{Funding}

The author (s) received no financial support for the research, authorship and/or publication of this article.

\section{Availability of data and materials}

The datasets used and/or analyzed during this study are available from the corresponding author on reasonable request.

\section{References}

1- World Health Organization. The ICD-10 classifications of mental and behavioral disorders: Clinical descriptions and diagnostic guidelines. Geneva: World Health Organization; 1992.

2-American Psychiatric Association. Diagnostic and statistical manual of mental disorders - 5. Washington, DC: American Psychiatric Association; 2013.

3- Weiner IB, Craighead WE. The corsini encyclopedia of psychology. Hoboken, New Jersey, US: John Wiley \& Sons; 2010.

4- Millon T, Davis R. Disorders of personality: DSMIV and beyond, 2nd ed. Oxford, England: John Wiley \& Sons; 1996. 
5-Shedler J, Westen D. Refining personality disorder diagnosis: integrating science and practice. Am J Psychiatry2004; 161(8), 1350-65.

6- Kraus G, Reynolds D. The "A-B-C's" of the cluster B's: identifying, understanding, and treating cluster B personality disorders. Clin Psychol Rev2001; 21(3): 345-73.

7- Nestadt G, Romanoski A, Chahal R, Merchant A, Folstein MF, Gruenberg EM, McHugh PR. An epidemiological study of histrionic personality disorder. Psychol Med1990; 20(2): 413-22.

8- Disney KL, Weinstein Y, Oltmanns TF. Personality disorder symptoms are differentially related to divorce frequency. J Fam Psychol2012; 26(6), 959-65.

9- Bockian NR. Depression in histrionic personality disorder. In Personality guided therapy for depression. Washington, DC, US: American Psychological Association; 2006. pp: 169-86.

10- Millon T, Millon C, Davis RD, Grossman S. Millon clinical multiaxial inventory-III (MCMI-III). London, UK: Pearson; 2009.

11- Hathaway S, McKinley J. MMPI-2: Manual for administration and scoring. Minneapolis: University of Minnesota Press; 1989.

12- Colligan R, Morey L, Offord K. The MMPI/MMPI-2 personality disorder scales: Contemporary norms for adults and adolescents. J Clin Psychol1994; 50(2): 168-200.

13-Ferguson CJ, Negy C. Development of a brief screening questionnaire for histrionic personality symptoms. Pers Individ Dif2014; 66, 124-7.

14- Marnat GG. Handbook of psychological assessment.
Hoboken, New Jersey, US: John Wiley \& Sons; 2003. 15- Khajeh Moogi N. Preliminary preparation of the persian form of Millon Clinical Questionnaire-2 in Tehran. [thesis]. Clinical psychology. Tehran: Psychiatric Institute, Iran University of Medical Sciences 1993; pp: 71-82.

16- Costa PT, Mccrae RR. Revised NEO Personality (NEO-PI-R) and NEO Five-factor Inventory (NEO-FFI) Professional manual. Odessa, Florida, US: Psychological assessment resources; 1992.

17- Haq Shenas H. Personality psychology. Shiraz, Iran: Shiraz university press; 2009. pp: 40-8.

18- Jöreskog KG, Sörbom D. LISREL 8.80 for windows (Computer Software). Lincolnwood, IL: Scientific Software International, Inc; 2006.

19- Brown TA. Confirmatory factor analysis for applied research. New York, US: Guilford publications; 2014

20- Schermelleh-Engel K, Moosbrugger H, Müller H. Evaluating the fit of structural equation models: Tests of significance and descriptive goodness of fit measures. Psychol Res2003; 8(2): 23-74.

21- Hair JF, Black WC, Babin BJ, Anderson RE. Multivariate data analysis. Upper Saddle River, NJ: Pearson prentice hall; 2006.

22- Hu LT, Bentler PM. Cutoff criteria for fit indexes in covariance structure analysis: conventional criteria versus new alternatives. Structural Equation Modeling A: Multidisciplinary Journal1999; 6(1): 1-55.

23- Tabachnick BG, Fidell LS. Using multivariate statistics, 5th ed. Boston, MA: Pearson; 2007

Copyright $(2016$ ASP Ins. This open-access article is published under the terms of the Creative Commons Attribution-NonCommercial 4.0 International License which permits Share (copy and redistribute the material in any medium or format) and Adapt (remix, transform, and build upon the material) under the Attribution-NonCommercial terms. 